\title{
CAMPESINADO Y NACIÓN
}

\section{Comentarios sobre Peasant and Nation. The Making of Postcolonial Mexico and Peru de F̈lorencia Mallon}

\section{Viviane Brachet-Márquez}

México y Perú tuvieron puntos de partida muy similares: fueron importantes centros de civilización indígena y de dominación colonial. Con la independencia, ambos atravesaron por un período de medio siglo de desorden político y económico. Sin embargo, al entrar al siglo XX, tenían trayectorias políticas muy distintas. ¿Por qué? Esta es la pregunta que plantea Florencia Mallon en Peasant and Nation $(\mathrm{P} \& \mathrm{~N})^{1}$. Para explicar tal divergencia, la autora analiza los movimientos $y$ «discursos populares", entendidos como una combinación de luchas y significados culturales compartidos. Argumenta que éstos representaron fuerzas que encaminaron sus países respectivos hacia el Estado-nación democrático. A pesar de haber sido en gran parte reprimidos y marginados por sus propios aliados, fueron fundamentales en la construcción de las estructuras políticas de México y Perú, tanto de ayer como de hoy. Con ello, la autora ofrece restituir las historias regional y local a la nacional, demostrando que las clases subordinadas no fueron sólo

${ }^{1}$ Florencia Mallon, Peasant and Nation. The Making of Postcolonial Mexico and Peru, University of California Press, 1995. 
objetos, sino también sujetos históricos en la formación de las naciones en estos dos países.

Mallon plantea que la formación del Estado en estos dos países se conforma a partir de una ideología nacionalista entendida como «una visión amplia que organiza la sociedad, un proyecto de identidad colectiva basado en la premisa de ciudadanía «disponible para todos y con la membrecía individual basada en el supuesto de la igualdad legal» (p. 4). No obstante, no hay un solo proyecto nacionalista, sino competencia entre varios de ellos. Por lo tanto, el proceso de formación de la nación es representado como un conjunto de discursos en pugna y en movimiento constante. Este se materializa en las historias regionales de las relaciones de poder.

¿Cómo llegan los diferentes proyectos de nación a un acuerdo? A través de un "proceso hegemónico» entendido en el sentido gramsciano, que encuentra, en un momento dado, un punto histórico de cristalización:

"La hegemonía es un conjunto de procesos continuos insertados unos en los otros a través de los cuales se disputan, se legitimizan y se redefinen el poder y los significados en todos los niveles de la sociedad. En segundo lugar, la hegemonía es un punto de llegada real, o sea, el resultado de procesos hegemónicos. Siempre un equilibrio dinámico y precario, un contrato o un arreglo se logran entre las fuerzas en pugna (...), los que ocupan el poder son capaces, de esta manera, de imponerse por medio de una combinación de coerción y consenso" (p. 6).

Para lograr establecer estos arreglos precarios, las élites deben incorporar, de alguna manera, las aspiraciones políticas y los discursos de los grupos subalternos que los apoyan, porque «sólo así pueden gobernar sobre la base de una combinación de coerción y consenso, y efectivamente traer una «revolución cultural» (p.7). El punto final en esta articulación es la construcción histórica de un pacto de dominación reconocido por la mayoría de la población por medio de procesos hegemónicos. Por lo tanto, para que pueda 
surgir un Estado nacional, los discursos distintos tienen que tener una resolución.

La contribución dinámica de los grupos subalternos a la formación del Estado nacional, sin embargo, es parcial, y acabará siendo sumergida y refundida por los grupos dominantes dentro de las coaliciones victoriosas. Qué tanto lo será es un hecho contingente que no puede téorizarse a priori. En el caso de México, hubo un acomodo relativo de las demandas de ciudadanía que pudo recuperarse en el momento de la Revolución de 1910, mientras que, en el caso peruano, la aportación campesina al pacto de dominación fue marginada al extremo. Esto tuvo como consecuencia la gran fragilidad del Estado nacional peruano hasta nuestros días.

La teorización que propone Mallon para interpretar los datos históricos es un intento muy ambicioso de construir un puente entre procesos culturales: los discursos, la identidad, las aspiraciones, los proyectos de liberación a través de la ciudadanía por un lado, y los procesos políticos por el otro, en otras palabras, las luchas para definir y redefinir las relaciones de desigualdad y dominación. Aquí, la cultura no es un todo homogéneo y estático, sino un complejo proceso atravesado por las jerarquías de clase, de género y de etnicidad. De esta manera, las luchas campesinas por la ciudadanía son condicionadas y dinamizadas por procesos culturales internos a las comunidades campesinas.

El cuerpo principal del libro es una narrativa extraordinariamente detallada de las luchas campesinas en la sierra de Puebla y el estado de Morelos en contra de la invasión francesa en México (1862-67), y en Junín y Cajamarca en contra de la invasión chilena en Perú (1879-84). Pese a las grandes semejanzas entre los puntos de partida de los países, Mallon llama la atención sobre diferencias importantes. En México, las luchas por la independencia se iniciaron con unas luchas populares en el Bajío, que, aunque fueron derrotadas, tuvieron consecuencias de largo plazo: algunos líderes supervivientes pudieron negociar con el nuevo poder independiente en 1821, y los campesinos morelenses y poblanos estuvieron aliados con una facción federalista. Ésta tuvo poder brevemente en la década de 1820, pero su momento importante fue 


\section{VIVIANE BRACHET-MÁRQUEZ}

después de 1855, con la revolución liberal y la intervención francesa, cuando se abrió una oportunidad histórica más amplia para las aspiraciones locales de ciudadanía. En Perú, en cambio, la represión de la rebelión de Túpac Amaru (entendida como un proyecto protonacionalista) en los años 1780 bloqueó las posibilidades de participación indígena en las luchas de independencia (en las que, dicho de paso, tampoco participaron mucho las élites peruanas). De ahí que las élites fueran incapaces de conectarse con los «intelectuales» rurales locales durante la guerra del Pacífico. Como resultado de esta divergencia inicial, el liberalismo, entendido como ideología revolucionaria, tuvo más éxito en México que en Perú, donde podía apoyarse en tradiciones pasadas de lucha y pudo tener mayor desarrollo posterior, aunque contradictorio.

En ambos países, la promesa de un proyecto nacional democrático universalista tuvo un efecto movilizador de las clases subalternas, que se estimularon con la presencia de un ejército extranjero en el suelo nacional: todos debían sacrificarse para defender el país, sin importar la clase social. Esto permitiría a los participarites en tal defensa formar parte de la nación naciente y recibir como recompensa la ciudadanía. Cuando las élites pidieron la participación campesina en la defensa, las comunidades campesinas de las regiones estudiadas respondieron en ambos países (mas no las de otras regiones, debe enfatizarse): con montoneras en Perú y con guardias nacionales en México. Dentro de este espacio de lucha, los campesinos participantes construyeron un proyecto nacional democrático.

El proyecto de los montoneros en Perú y de las Guardias Nacionales en México no era el de los liberales, insiste la autora, sino un proyecto propio, basado en la noción de responsabilidad y solidaridad comunal que se insertaba en el proyecto más amplio de libertad democrática. Al mismo tiempo, el proyecto subalterno era frágil e internamente fragmentado, porque era el resultado de un proceso hegemónico atravesado por jerarquías de etnicidad, género y clase. El proyecto comunal se enfrentaba, por otro lado, a las prácticas exclusionistas de las élites liberales. Pasada la amenaza de la ocupación extranjera, la alianza democrática popular se fue desmoronando. Empezaron guerras civiles de aniquilación de 


\section{CAMPESINADO Y NACIÓN}

los antiguos aliados, cuyas demandas se volvieron inaceptables. La ruptura de la alianza se hizo a sangre y fuego en ambos países. Pero, aun así, Mallon ve una diferencia entre Perú y México. En México, los movimientos populares siguieron aliándose hasta los años 1870 con facciones opositoras, especialmente la dirigida por Porfirio Díaz. A través de todo el Porfiriato, la tradición radical de los pueblos de la sierra de Puebla y de Morelos fue conservada en los archivos y la memoria colectiva, lo que hizo posible la preservación de la cultura política popular radical, la que había permanecido intacta en 1910 cuando estalló la revolución, y así pudo participar en el nuevo proyecto nacional. Posteriormente, el Estado posrevolucionario incorporó parte de la agenda popular que había sido construida en los años 1850.

En Perú, la administración de Piérola durante los años 1890 reprimió el proyecto popular e impidió el voto indígena, reproduciendo la fragmentación colonial étnica. Para 1900, el proyecto peruano de construcción de un Estado democrático nacional había sido abandonado y se había cristalizado un sistema de élites étnica y regionalmente fragmentadas En 1968, el intento de crear un proyecto democrático nacional fracasó, así como el que se dio en los años 1980. De la democracia de los 90 el libro no habla.

Lo primero que debe decirse sobre este libro es la fascinación que crea en el lector, a quien lleva por los laberintos de la micropolítica, revelando un proceso extraordinariamente complejo, basado en un trabajo de archivo verdaderamente virtuoso. Además, es un libro placenteramente legible, lo cual es un tour de force, dada la densidad del material analizado y la complejidad de los argumentos que le subyacen. Es un maestro libro, sin lugar a duda, que merece un lugar eminente entre las obras que restituyen su papel histórico a las clases subordinadas, así como las que hacen palpable la discusión, a veces demasiado esotérica, de la relación entre agencia y estructura.

Los libros maestros reciben cuantiosos homenajes, como se lo merecen. Pero también son blanco de abundante crítica. Esto es así por dos razones: la primera, la menos importante, pero inicialmente la más visible, es porque habrá muchos «colegas» quienes, en el fondo, quisieran haber podido escribir tal libro, pero, al no 
haberlo hecho, utilizan su energía para achicarlo y, de ser posible, derrumbarlo ${ }^{2}$. La segunda es mucho más sustantiva y positiva: para sacar el máximo provecho de una obra como ésta hay que radiografiarla, desempacarla, desarmar y rearmarla y, finalmente, sacar una buena copia de las refacciones que pueden servirle a uno, así como proponer otras disponibles, pero que no fueron utilizadas. En estos comentarios me abocaré a esta operación pirata.

El relato demuestra en forma contundente la capacidad de las comunidades campesinas para actuar estratégicamente, para negociar y para conformar alianzas cambiantes con élites en pugna. Demuestra también su voluntad de cambio frente al aferramiento de las élites a las tradiciones. Esto contrasta con dos imágenes estereotipadas que han estado presentes en la literatura del pasado: la del campesinado pasivo, políticamente inculto y sólo capaz de acción irracionalmente violenta, por un lado, y la de las élites liberales, agentes históricos de la democracia y de la modernidad, por otro. Las élites latinoamericanas, aun las «liberales», fueron extraordinariamente tradicionalistas, mientras que los campesinos lucharon por la igualdad ante la ley. Este aporte, quizás, ya no es nuevo, pero es un buen aporte en esta literatura que resalta la actuación de los de abajo en los grandes procesos históricos. Lo que puede cuestionarse, y de hecho ha sido cuestionado, es que la bandera legalista que enarbolaron los campesinos en sus luchas fuera evidencia del trasfondo democrático de su «discurso», en vez de una palanca estratégica para defender sus intereses estrechamente concebidos o, como dice la autora, pensar con el estómago. Este cuestionamiento, sin embargo, puede hacerse de cualquier grupo que se haya reclamado partidario de cualquier principio democrático en medio de un proceso de lucha por el poder. Cuando los representantes del Tercer Estamento en la Asamblea de los Estamentos Generales de 1789 en Francia se reclamaban partidarios del principio de un voto por cabeza (en oposición al voto por estamento que preferían la nobleza y el clero), ¿lo hacían por «de-

${ }^{2}$ Una señal clara de esta voluntad mezquina de destrucción es cuando las reseñas dedican párrafos enteros a subrayar los errores ortográficos, de traducción o de estilo. Es una forma de corroer la obra sin arriesgarse demasiado. 


\section{CAMPESINADO Y NACIÓN}

mocráticos» o porque sólo de esta manera podían adquirir alguna porción de poder que les permitiera defender sus intereses? Y, después de todo ¿qué es la democracia? No es un discurso unificado que se ofrezca en paquete completo con instrucciones de cómo usarlo, sino una serie discontinua, internamente contradictoria $e$ históricamente construida a partir de procesos hegemónicos complejamente entretejidos ( $y$, dicho sea de paso, nunca acabados, porque la democracia, al igual que la historia, nunca se acaba). Pero el postulado planteado por la autora de que las ideologías liberales hayan penetrado en las comunidades campesinas de mediados de siglo es poco dudoso, y tampoco lo es de que hubieran tenido sus vertientes heroicas y patrióticas en algunos de los pueblos involucrados en las dos guerras. De lo contrario, ¿qué sentido hubiera tenido, para los habitantes de un pueblo como Xochiapulco, en la sierra de Puebla, pelear como lo hicieron en la batalla de Puebla y luego preferir quemar sus casas antes que rendirse a los soldados austro-belgas mandados por Maximiliano? De igual manera, ¿qué sentido hubiera tenido para los campesinos peruanos de Junín y Cajamarca arriesgar el todo por el todo ante un invasor que difería muy poco de los hacendados locales? En realidad, no es necesario escoger entre heroísmo e idealismo. Basta con reconocer que los campesinos, tanto del Perú como de México, combatieron por una definición de las reglas de gobernar que los incluyera. Que estos anhelos fueran protodemocráticos, democratizantes o simplemente pragmáticos es debatible. Lo importante es restituir a estos campesinos la calidad de actores políticos con intereses y principios de definidos autoctónamente, en otras palabras, como agentes del proceso de formación del Estado nacional.

La narrativa también ilustra en forma variada y rica lo anunciado al principio del libro: que la historia nacional resulta ser un collage de hechos y mitos compilados por los vencedores. En particular, se denuncia el mito según el cual el nacionalismo latinoamericano del siglo pasado haya sido un proyecto central con una ideología clara y un liderazgo inspirado por la tradición europea de la Ilustración. Es sorprendente, por ejemplo, descubrir que muchos sucesos presentados como historia nacional en México (aun por 


\section{VIVIANE BRACHET-MÁRQUEZ}

los historiadores serios, no digamos por los oficiales) son en realidad fragmentos recortados y revisados de la historia regional y local disfrazados de nacionales. En esto se hace evidente que los que logran imponer su versión de la historia no son simplemente la coalición vencedora, sino las élites dentro de ella, las mismas que muy pronto "desaparecen» a sus aliados de antaño ${ }^{3}$. Lo importante aquí es que la historia regional que nos presenta la autora no es una mera curiosidad historiográfica, sino una parte operante de lo nacional, pero en una versión muy distinta de la escrita por los vencedores y acríticamente avalada por las generaciones posteriores. Esto contrasta con la enorme cantidad de historias regionales que persiguen el detalle historiográfico sin tener objetivo teórico alguno y que llenan las bibliotecas del mundo, sobre todo en América Latina.

Más allá de la reconstitución minuciosa del telar histórico, el libro plantea argumentos teóricos que abren nuevas discusiones o aportan nuevos elementos a viejas polémicas. Sólo podré tocar unas cuantas en estos comentarios. Una primera es el uso de la noción de hegemonía como bisagra del cambio histórico, y la otra es la conceptualización de nación como inseparable de ciudadanía, y por ende de democracia.

Hegemonía, en el sentido utilizado por la autora, indica, a la vez, el proceso de lucha por el poder e institucionalización de los significados. En segundo lugar, hegemonía se refiere al punto final de tal proceso, entendido como «contrato o acuerdo concertado entre las fuerzas en pugna» (p. 6). Para facilitarnos la tarea, llamémoslas hegemonia-1 y hegemonia-2. Aquí la autora quiere hacer hincapié en el hecho de que hegemonía-1 es la dinámica de las acciones y proyectos en pugna dentro de un espacio nacional (o

${ }^{3}$ Es interesante anotar que, en el caso de la revolución mexicana, sucedió algo un poco distinto, pero parecido en el fondo. Las élites constitucionalistas primero utilizaron la fuerza militar zapatista y villista para vencer al neoporfirismo, luego destruyeron los movimientos portadores de demandas de reforma social que estas fuerzas representaban, para, finalmente, reintroducir algunas de sus demandas en la Constitución de 1917, pero más como símbolos legitimadores que como compromisos políticos reales, como la historia siguiente demostró. 
multirregional) dado, en otras palabras, agencia, pero también es estructura, en el sentido de cristalización (precaria y provisional) de estas pugnas en arreglos de poder o hegemonía-2. La ventaja de tal planteamiento es no separar agencia de estructura. La desventaja es que, cada vez que aparece la palabra hegemonía en el texto, el lector debe cerciorarse con la ayuda del contexto de cuál de las dos hegemonías se trata. Esta gimnasia mental se complica aún mas cuando se introduce la noción de "pacto de dominación» (un concepto con un largo pedigrí en América Latina que, sin embargo, no se cita) cuya definición es casi sinónima de la de hegemonía-2, pero, en vez de un conjunto de los discursos en pugna, nos presenta una «red de formas de poder traslapadas» controlada por un Estado dotado de intereses propios (p. 10). Tal aseveración sorprende, dado que el libro trata del proceso temprano de la formación del Estado en los dos países, cuando éste es poco más que un espacio de luchas hegemónicas inestables. Por lo tanto, resulta difícil imaginar una diferenciación clara en tal espacio entre los intereses de las élites gobernantes de turno y los intereses propios de un Estado maduro "a la Skocpol", que buscaría velar por la estabilidad y la reproducción de un pacto de dominación definido. Este último concepto, por lo tanto, sobra, porque se acerca demasiado a hegemonía-2, y además no se utiliza en el resto de la obra. Quizás la solución es utilizarlo en sustitución de la noción de hegemonía-2, lo cual evitaría la ambigüedad señalada de este concepto. La noción de pacto de dominación resulta más sugerente como visión estructural, porque indica implícitamente un contenido sustantivo de tal pacto sustentado en las instituciones y la ley, mientras que la noción de hegemonía se presta más a lo fluido y cambiante, en el sentido dado a hegemonia-1.

Finalmente, es necesario desatar el nudo conceptual que entremezcla las nociones de Estado, nación y Estado-nación. Aunque parezcan similares, están muy lejos del grado de integración que hace suponer el libro. Nación, como bien lo nota Mallon, implica ciudadanía o un conjunto de derechos individuales sin los cuales las libertades democráticas fundamentales (de igualdad ante la ley, de capacidad de elegir o ser elegido en representación de la colectividad, de ser protegido de la arbitrariedad estatal, etc.) no 


\section{VIVIANE BRACHET-MÁRQUEZ}

pueden ser ejercidas. El Estado, en cambio, se refiere al poder que ejerce un cuerpo administrativo/militar sobre la población comprendida dentro de un territorio dado. Por lo tanto, la noción de Estado para nada tiene una asociación automática con la de nación, no obstante la denominación común de Estado-nación para designar prácticamente cualquier país contemporáneo. Habrá cantidad de Estados que no se rigen por principios democráticos, pero, sin embargo, tienen poder sobre un territorio dado y gozan de cierta legitimidad, aunque no necesariamente basada en la ciudadanía. Basta con regresar al texto de Weber para redescubrir en sus descripciones de los Estados patrimoniales cuantiosos rasgos de los Estados latinoamericanos contemporáneos. El término nación, igualmente, ha venido a ser utilizado como sinónimo de Estadonación, lo cual escamotea el significado de ciudadanía que le subyace. En $\mathrm{P} \& \mathrm{~N}$, estas confusiones son reproducidas acríticamente. El problema no es un simple formalismo definitorio. Resulta que los territorios cuya historia el libro nos narra no son naciones y tampoco tienen Estados en el momento del estudio. Por un lado, tienen una ciudadanía demasiado restringida para poder aspirar a ser naciones $y$, por otro, sus aparatos administrativo/militares no detienen el monopolio de la fuerza ni son capaces de implementar un cuerpo de reglas uniformemente sobre su territorio. Peor aún, la definición de la extensión de sus territorios está en pugna, con autoridades estatales múltiples compitiendo por la apelación de Estado. Esto es lo que corresponde, en el lenguaje de Charles Tilly, a una situación revolucionaria donde ningún grupo logra imponer su regla $y$, por consiguiente, no puede establecerse ningún pacto de dominación.

Esta crítica no le resta nada a la pretensión de la autora de que los campesinos estudiados hayan participado en la formación del Estado y hayan tratado de darle un giro democratizante a tal proceso (por las razones ideológico/prácticas que sean). Al contrario, el reconocimiento de una situación revolucionaria exenta de Estado (y a fortiori de nación) admite tal argumento, pero a la vez resalta lo contingente del resultado final, cuando, a pesar de tales esfuerzos, lo democrático naciente se vio sumergido por el porfirismo en México y por el pierolismo en Perú. Tal encuadre también resal- 
ta lo excepcional de la situación estudiada: se trata de una coyuntura crítica durante la cual la historia puede bifurcarse bajo el impulso de agentes específicos. Los agentes, en tales coyunturas, no son el conjunto del campesinado, sino precisamente unos grupos selectos.

En este último contexto, la cuestión de si los campesinos de Cajamarca o Puebla fueron excepcionales, y por lo tanto su caso no puede extrapolarse a otros campesinos, se vuelve irrelevante. En momentos de ruptura son las excepciones y no la masa las que arrancan el proceso de contestación de un pacto de dominación. Estos grupos excepcionales son el punto de lanza de un nuevo proceso de hegemonía-1 y, por lo tanto, su acción no corresponde a la lógica estadística de recurrencia regular, sino a la de contagio y difusión a partir de un foco único. En otras palabras, representan el ejemplo excepcional que da energía a los demás, posibilitando lo imposible. Así, la rebelión hidalguense fue excepcional y fue derrotada, pero, como argumenta Peter Guardino en otro libro muy interesante sobre el mismo tema, la insurgencia campesina siguió y duró hasta 1820 sin el impulso de ningún hacendado ${ }^{4}$.

¿Qué legados han quedado de estos momentos heroicos en la actualidad? Mallon nos indica que la tradición campesina radical fue recogida por la revolución en México, mientras que en Perú prácticamente se perdió por la ausencia de nichos opositores para protegerla. Si es así, ¿por qué es México uno de los últimos países de América Latina en democratizarse?, y ¿cómo es que su campesinado ha sido el peor servido en la mesa revolucionaria? Quizás hay diferentes formas de negar la participación campesina en la formación del Estado en América Latina. Una es la negación rotunda, la otra es la celebración de mitos revolucionarios sin trasfondo real.

${ }^{4}$ Peter Guardino, Peasants, Politics and the Formation of Mexico's National State, Stanford University Press, 1996. 